\title{
Kajian Historis Arsitektur Dan Terminologi Rumah Adat Dalam Loka Sumbawa
}

\author{
Sri Wahyu Hidayati \\ Dosen Ilmu Sejarah, Fakultas Budaya Institut Ilmu Sosial dan Ilmu Budaya Samawa Rea \\ (IISBUD SAREA), Sumbawa Besar \\ E-Mail: Wahyuyayuk21@gmail.com
}

\begin{abstract}
Abstrak. Rumah tradisional Sumbawa rumah adat Istana Tua (Dalam Loka) yang dahulunya digunakan sebagai istana Raja Kesultanan Sumbawa. Rumah adat itu berlokasi di Kota Sumbawa, Kabupaten Sumbawa, Nusa Tenggara Barat.Rumah adat Istana Tua (Dalam Loka) yang berupa rumah panggung, mencerminkan bentuk kebudayaan masa lampau. Rumah adat Dalam Loka masih berdiri kokoh di tengah kota Sumbawa Besar, merupakan saksi sejarah yang memperlihatkan kejayaan Kesultanan Sumbawa. Kekayaan yang terdapat dalam rumah adat Dalam Loka, memberikan ruang bagi peneliti dan budayawan untuk memahami lebih dalam apa saja yang terjadi di masa lampau berdasarkan symbol-simbol yang menyiratkan bagaimana kehidupan zaman dahulu sarat makna yang mendalam. Nilai sejarah dan nilai budaya yang dimiliki dalam rumah adat Dalam Loka, perlu ditelusuri melalui pendekatan berdasarkan kajian historis. Tujuan penulisan ini adalah, untuk mengetahui sejarah dan nilai budaya dalam arsitektur Istana Tua (Dalam Loka). Metode penelitian yang digunakan bersifat deskriptif dengan pendekatan kualitatif. Teknik pengumpulan data berupa wawancara, pengamatan, dan studi pustaka. Hasil dan pembahasan dalam penelitian ini, ditemukan nilai historis dalam rumah adat Dalam Loka Sumbawa berasal bahasa-bahasa nusantara, yaitu berasal dari bahasa Jawa, Makassar dan Melayu. Selain itu rumah adat Dalam Loka Sumbawa berasal dari bahasa asing, seperti bahasa Arab dan bahasa Sanskerta. Nilai budaya dalam rumah adat Dalam Loka Sumbawa menunjukkan keberadaan sebuah pradaban dengan sistem pemerintahan dan sistem kerajaan dalam bentuk aristokrasi. Tatanan pemerintahan yang bertumpu pada raja (sultan) adalah sebuah sistem yang mencakup adat, pemerintahan dan hukum.
\end{abstract}

\section{Kata Kunci: Arsitektur, Terminologi Rumah Adat Dalam Loka}

\section{PENDAHULUAN}

Indonesia adalah salah satu negara yang memiliki kebudayaan dan kearifan local Kebudayaan dan kearifan lokal tersebut terbentuk sebagai hasil dari proses interaksi antara manusia dengan lingkungan dalam rangka memenuhi berbagai kebutuhan. Manusia dalam kehidupannya mempunyai banyak kebutuhan hidup (Suriasumantri, 1996: 261). Adanya kebutuhan hidup ini mendorong manusia untuk melakukan berbagai tindakan dan kebiasaan yang bermanfaat untuk mempertahankan dan mengembangkan cara hidupnya. Perkembangan cara hidup manusia dapat dilihat dari cara bagaimana mereka menata peradabannya (Sibarani, 2004).

Di antara berbagai pulau yang tersebar di kepulauan di Nusa tenggara terdapat sebuah pulau besar yang dikenal dengan pulau Sumbawa, meskipun pulau ini berdekatan dengan pulau Lombok danpulau Bali yang sudah banyak dikenal budaya maupun Arsitekturnya, masih jarang oraang memperhatikan secara lebih cermat dan mendetail, terutama dari sudut pembacaan tanda visual atau semiotikaarsitektur. Pada dasarnya, Sumbawa merupakan sebuah pulau di mana tradisi dan kebudayaan masih sangat kental terlihat dan terpelihara hingga kini. Hal tersebut bahkan Nampak kita jumpai pada cara berhuni mereka. Akan tetapi, sangat disayangkan jika pergeseran mulai terlihat akhir-akhir ini dikarenakan semakin gencarnya intervensi budaya dari luar yang lebih mendominasi dan menjadi tren bagi remaja disana. Jika ditilik dari keragaman rumah adat Sumbawa, akan kita jumpai beragam penampakan visual, baik dimensi, proporsi, peruntukan dan ragam hiasnya. 
Beberapa di antaranya yang dapat kita jumpai yaitu bangunan rumah adat dalam loka, rumah adat bale Pekat dan rumah adat bale Panggung. Sebagai aset kebudayaan Nusantara perlu kiranya keberadaan artefak arsitektur tersebut dikaji dan dilestarikan, karena sampai saat ini belum ada informasi yang jelas hanya sebatas observasi lapangan dan wawancara dengan pemangku adat. Nampaknya Rumah Adat tersebut penuh dengan makna, sehingga melalui bahasa visual aset tersebut di analisis berdasarkan aspek aspek semiotikanya. Sebagai aset penting Arsitektur Nusantara yang perlu didokumentasikan agar bisa dijadikan pengembangan desain Arsitektur yang berciri lokalitas, Khususnya wujud tanda visual perlu adanya.

Arsitektur tradisional Nusantara sangat beragam sesuai suku yang ada mulai dari Kepulauan yang paling barat di ujung pulau Sumatra sampai paling timur di pulau Papua terdapat beranekaragam rumah tradisional dengan aneka corak dan ragamnya masing-masing. Ragam visual dalam rumah tradisional tersebut sudah barang tentu menjadi sarana komunikasi visual yang digunakan oleh masyarakat setempat. Arsitektur lebih dari sekedar sebuah perakitan bahan didirikan diatas sebidang lahan, akan tetapi merupakan sebuah manifestasi dari masalah yang beragam (Khairil 2017).

Dalam naskah kuno sastra Jawa dan kitab Buku Tana Samawa secara jelas dapat ditemukan relevansi antara lingkungan dan kehidupan budaya manusia, hal tersebut terwujud pada penggambaran bentuk rumah adat yang diciptakan.Tata cara pembuatan rumah menurut konsep arsitektur tradisional Tau Samawa (orang Sumbawa), merujuk pada pesan atau wasiat yang bersumber dari kepercayaan dan adat istiadat yang dianut masyarakat Sumbawa, mulai dari pemilihan tempat, penentuan arah peletakan rumah, bentuk arsitektur, hingga penyelenggaraan upacara ritual ketika proses pembangunannya. Mardanas, menyatakan bahwa orang-orang dahulu, tata wilayah dan tata bangunan yang secara populer disebut arsitektur tidak diarahkan pertama kali demi penikmatan rasa estetika bangunan, tetapi terutama demi kelangsungan hidup secara kosmis (Mardanas, 1985).

\section{TINJAUAN PUSTAKA}

Arsitektur merupakan salah satu aspek kebudayaan merupakan perwujudan nilai-nilai yang dianut dan dipelihara untuk diwariskan pada generasi berikutnya. Hal tersebut sejalan dengan pernyataan Yudono yang disitasi oleh Henny dan Yamin (2018) bahwa: "semakin cepat dilakukan kajian untuk menggali kearifan arsitektur tradisional lokal semakin baik, sebelum para sesepuh, cerdik cendekia bidang budaya, sosiologi dan arsitektur tradisional terlanjur berpulang, sehingga local wisdom architecture tacit knowledge yang sangat diperlukan oleh generasi penerus dapat dirajut kembali”. Selanjutnya Anwar (2005) berpendapat bahwa kurangnya pemahaman makna dan nilai tentang arsitektur lokal, dikhawatirkan akan mengakibatkan hilangnya jati diri. Arsitektur sebagai salah satu aspek kebudayaan merupakan perwujudan nilai-nilai yang dianut dan dipelihara untuk diwariskan ke generasi berikutnya. Bahwa penutur asli Istana Tua (Dalam Loka) kurang mampu menyampaikan secara sistematis dan juga sudah mulai uzur dan pupus; yang apabila tidak diregenerasikan maka identitas arsitektur akan hilang. Dilain pihak, lebarnya kesenjangan pemahaman dan persepsi tentang arsitektur diantara para pelaku pambangunan.

Menurut Saliya (2003), mengatakan bahwa arsitektur tradisional pada dasarnya tidak mengenal ukuran yang formal seperti meter atau feet. Ukuran yang digunakan adalah selalu bersifat kongkrit yakni merujuk pada ukuran atau besaran benda, misalnya: ukuran bagian tubuh manusia, seperti depa, hasta, tinggi pundak, rentangrentang tegak dan lebar langkah. Besaranbesaran ini selalu dikaitkan dengan memerlukan sebuah sistem tulisan. Tradisi sering dianggap sesuatu yang kuno tapi sangat penting untuk dijaga. Dalam paparan teoritis, tradisi bisa dipandang sebagai informasi atau terdiri atas informasi ataupun 
data. Informasi yang dibawa dari masa lalu ke masa sekarang. Sehingga informasi ini dapat dianggap sebagai bagian yang paling mendasar walaupun secara fisik ada kegiatan atau aktifitas tertentu yang dilakukan secara terus menerus dan berulang. Dengan demikian tradisi adalah sebuah kegiatan yang dilakukan secara terus menerus, berulang ulang, atau sebuah kebudayaan atau sebuah hasil karya yang dianggap berhasil dan memiliki legitimasi dalam kurun waktu yang panjang yang diikuti oleh generasi-generasi berikutnya secara turun temurun.

Arsitektur Tradisional Sumbawa Arsitektur sebagai salah satu aspek kebudayaan merupakan perwujudan nilainilai yang dianut dan dipelihara untuk diwariskan pada generasi berikutnya. Hal tersebut sejalan dengan pernyataan Yudono yang disitasi oleh Henny dan Yamin (2018) bahwa: "semakin cepat dilakukan kajian untuk menggali kearifan arsitektur tradisional lokal semakin baik, sebelum para sesepuh, cerdik cendekia bidang budaya, sosiologi dan arsitektur tradisional terlanjur berpulang, sehingga local wisdom architecture tacit knowledge yang sangat diperlukan oleh generasi penerus dapat dirajut kembali". Selanjutnya Anwar (2005) berpendapat bahwa kurangnya pemahaman makna dan nilai tentang arsitektur lokal, dikhawatirkan akan mengakibatkan hilangnya jati diri. Arsitektur sebagai salah satu aspek kebudayaan merupakan perwujudan nilai-nilai yang dianut dan dipelihara untuk diwariskan ke generasi berikutnya. Bahwa penutur asli Istana Tua (Dalam Loka) kurang mampu menyampaikan secara sistematis dan juga sudah mulai uzur dan pupus; yang apabila tidak diregenerasikan maka identitas arsitektur akan hilang. Dilain pihak, lebarnya kesenjangan pemahaman dan persepsi tentang arsitektur diantara para pelaku pambangunan.

Menurut Saliya (2003), mengatakan bahwa arsitektur tradisional pada dasarnya tidak mengenal ukuran yang formal seperti meter atau feet. Ukuran yang digunakan adalah selalu bersifat kongkrit yakni merujuk pada ukuran atau besaran benda, misalnya: ukuran bagian tubuh manusia, seperti depa, hasta, tinggi pundak, rentangrentang tegak dan lebar langkah. Besaranbesaran ini selalu dikaitkan dengan nilainilai kosmologis yang memandang segala sesuatu terkait dan diposisikan terhadap alam semesta atau jagad raya yang merupakan bagian dari proses penciptaan alam raya. Hal tersebut sejalan dengan Ronald (2005) bahwa satuan ukuran yang digunakan untuk menentukan besaran panjang atau jarak, digunakan bagian tubuh mulai dari ibu jari, telapak tangan, telapak kaki dan panjang lengan atau yang lebih dikenal dengan ukuran antropometrik. Arsitektur tradisional sebagai salah satu bentuk warisan budaya merupakan pengendapan fenomena dari waktu ke waktu yang berlangsung secara runtut evolusioner dengan situasi budaya yang penuh konflik, perubahan atau perkembangan. Tuntutan akan makna dan identitas dari arsitektur semakin meningkat. Kurangnya penalaran kognitif dan penghayatan afektif atas maksud yang terkandung didalam arsitektur tradisional selama ini telah mengakibatkan munculnya bangunan-bangunan yang berbedak tradisional, komponen fisik dan wajah visualnya dipakai, tetapi hal-hal yang terkait dengan falsafah nilai, sistem perlambang dan pemaknaan sosial ditiadakan (Budihardjo, 1989).

\section{METODE}

Penelitian ini menggunakan pendekatan kualitatif untuk menggali obyekobyek visual dalam kawasan studi yang menurut pandangan masyarakat penduduk setempat memiliki tanda tanda atau simbol symbol tertentu bagi lingkungan. Tahap awal dilakukan observasi lapangan dan wawancara kepada masyarakat asli dan kunci. Hasil yang diperoleh dalam tahap ini digunakan sebagai acuan dasar untuk merekonstruksi konfigurasi visual dalam skala rumah tinggal, selubung luar bangunan dan ruang dalam serta detail ragam hias yang ada di rumah tinggal tersebut. Tahap selanjutnya, merekonstruksi konfigurasi visual dalam skala rumah tinggal, selubung 
luar bangunan dan ruang dalam serta detail ragam hias yang ada di rumah tinggal tersebut. Hasil rekonstruksi visual tersebut sebagai bahan stimuli untuk menggali penilaian masyarakat terhadap obyek-obyek visual tersebut, yang dilakukan dengan pendekatan kualitatif

\section{HASIL DAN PEMBAHASAN}

Kerajaan Samawa adalah salah satu dari tiga kerajaan Islam besar di pulau Sumbawa. Keberadaan Tana Samawa atau wilayah Sumbawa, mulai dicatat oleh sejarah sejak zaman Dinasti Dewa Awan Kuning, tetapi tidak banyak sumber tertulis yang bisa dijadikan bahan acuan untuk mengungkapkan situasi dan kondisi pada waktu itu. Sebagaimana masyarakat di daerah lain, sebagian rakyat Sumbawa masih menganut animisme dan sebagian sudah menganut agama Hindu. Baru pada kekuasaan raja terakhir dari Dinasti Awan Kuning, yaitu Dewa Maja Purwa, ditemukan catatan tentang kegiatan pemerintahan kerajaan, antara lain bahwa Dewa Maja Purwa telah menandatangani perjanjian dengan Kerajaan Gowa di Sulawesi. Perjanjian itu baru sebatas perdagangan antara kedua kerajaan kemudian ditingkatkan lagi dengan perjanjian saling menjaga keamanan dan ketertiban. Kerajaan Gowa yang pengaruhnya lebih besar saat itu menjadi pelindung Kerajaan Samawa. Menurut Zolinger, agama Islam masuk ke Pulau Sumbawa lebih dahulu dari pada Pulau Lombok antara tahun 1450-1540 yang dibawa oleh para pedagang Islam dari Jawa dan Sumatera, khususnya Palembang. Selanjutnya runtuhnya Kerajaan Majapahit telah mengakibatkan kerajaan-kerajaan kecil di wilayah Sumbawa menjadi kerajaankerajaan Sunan Prapen yang merupakan keturunan Sunan Giri dari Jawa datang untuk menyebarkan Islam pada kerajaankerajaan Hindu di Sumbawa, dan terakhir penaklukan Karaeng Moroangang dari Kerajaan Gowa tahun 1618 atas Kerajaan Dewa Maja Paruwa (Utan) sebagai kerajaan terakhir yang bersedia masuk Islam dijadikan tempat-tempat hunian berupa Rumah Tinggal yang secara arsitektural sangat beragam, mulai dari yang Tradisonal, Kolonial dan Modern sampai yang hibrida.

$$
\text { Khususnya Rumah Tinggal }
$$

Tradisional Sumbawa sudah jarang ditemui secara utuh dan masih dihuni atau dibangun kembali dengan cara masyarakat tradisi Sumbawa. Namun demikian masih ada yang representatif untuk mewakili sampel studi Rumah Tradisional Sumbawa dari sudut pandang bahasa visual atau Semiotika. Masyarakat Sumbawa secara tadisional terbagi dalam tiga strata sosial, yaitu keluarga kerajaan, pembesar kerajaan dan masyarakat biasa. Mereka masih ada meskipun sudah membaur dalam masyarakat umum. Rumah tinggal mereka semula berada dan terbangun dalam wujud yang menunjukan strara tersebut, bila dilihat secara visualnya. Rumah tinggal Tradisi mereka memiliki nama yang khusus bagi masyarakat Sumbawa, yaitu Dalam Loka, Bale Pekat dan bale Panggung. Dalam Loka adalah Rumah tinggal keluarga kerajaan atau istana, Bale pekat adalah rumah tinggal keluarga pembesar kerajaan sedangkan Bale Panggung adalah rumah tinggal rakyat umumnya. Rumah Tinggal Tradisional Sumbawa yang representatif untuk mewakili sampel studi Rumah Tradisional Sumbawa dari sudut pandang bahasa visual atau Semiotika diambil masing masing.

Sejarah Istana Tua (Dalam Loka) Pulau Sumbawa yang terletak di Propinsi Nusa Tenggara Barat telah didiami manusia sejak zaman glasiasi (1 Juta tahun yang lalu), dan mengawali masa sejarahnya mulai abad 14 Masehi ketika terjadi hubungan politik dengan kerajaan Majapahit yang saat itu berada di bawah kepemimpinan raja Hayam Wuruk dengan Maha Patihnya yang terkenal, Gajah Mada (1350-1389). Pada saat itu di Sumbawa dikenal adanya kerajaan Dewa Awan Kuning, yang memiliki vassal (Kadipaten) yaitu kerajaan Jereweh, Taliwang, dan Seran. Raja terakhir kerajaan Dewa Awan Kuning, Dewa Majaruwa memiliki kepercayaan Hindunisme yang kemudian memeluk agama Islam. Perubahan agama ini berkaitan dengan adanya hubungan dengan kerajaan Islam pertama di Jawa, yakni kerajaan Demak (1478-1597). 
Pada tahun 1623 kerajaan Dewa Awan Kuning ini ditaklukan oleh kerajaan Goa dari Sulawesi Selatan. Hubungan dengan kerajaan Goa kemudian diperkuat dengan perkawinan silang sebagai berikut: Pada 24 Desember 1650, raja Sumbawa, Mas Dini, menikah dengan puteri raja Tallo. Pada 29 Juni 1684, Mas Bantam, pendiri kerajaan Sumbawa dinasti Dewa Dalam Bawa bergelar Sultan Harunnurasyid I (16741702) menikah dengan putri raja Goa. Selanjutnya, putera kedua Sultan Harunnurasyid I, Mas Madina, yang kemudian menjadi raja dengan gelar Sultan Jalaluddin Muhammad Syah I (1702-1723), menikahi puteri raja Goa lainnya.

Pernikahan silang antar kerajaan ini dapat dikatakan sebagai perkawinan politik antara kerajaan Goa dengan kerajaan Sumbawa. Adapun Raja Sumbawa yang berkaitan langsung dengan pembangunan Istana Dalam Loka adalah Sultan Muhammad Jalaluddin Syah III (18831931), yang merupakan Sultan ke-16 dari dinasti Dewa Dalam Bawa. Sultan Muhammad Jalaluddin Syah III ini mendapat peneguhan sebagai penguasa Sumbawa berdasarkan akte Pemerintah Kolonial Hindia Belanda tanggal 18 Oktober 1885 dan mulai saat itulah penjajahan kerajaan Belanda berlangsung secara efektif di wilayah kerajaan Sumbawa. Luas wilayah kerajaan Sumbawa berdasarkan Lange Politick Contract 1938 adalah 844 km2, yang secara geografis merupakan sebagian dari Pulau Sumbawa yang terletak pada posisi $116035^{\prime} \mathrm{BB}$ - $118015^{\prime}$ BT dan 80 5' BU-90 5'-LS.Sejarah Istana Tua ( Dalam Loka) Pulau Sumbawa yang terletak di Propinsi Nusa Tenggara Barat telah didiami manusia sejak zaman glasiasi (1 Juta tahun yang lalu), dan mengawali masa sejarahnya mulai abad 14 Masehi ketika terjadi hubungan politik dengan kerajaan Majapahit yang saat itu berada di bawah kepemimpinan raja Hayam Wuruk dengan Maha Patihnya yang terkenal, Gajah Mada (1350-1389).

Pada saat itu di Sumbawa dikenal adanya kerajaan Dewa Awan Kuning, yang memiliki vassal (Kadipaten) yaitu kerajaan
Jereweh, Taliwang, dan Seran. Raja terakhir kerajaan Dewa Awan Kuning, Dewa Majaruwa memiliki kepercayaan Hindunisme yang kemudian memeluk agama Islam. Perubahan agama ini berkaitan dengan adanya hubungan dengan kerajaan Islam pertama di Jawa, yakni kerajaan Demak (1478-1597). Pada tahun 1623 kerajaan Dewa Awan Kuning ini ditaklukan oleh kerajaan Goa dari Sulawesi Selatan. Hubungan dengan kerajaan Goa kemudian diperkuat dengan perkawinan silang sebagai berikut: Pada 24 Desember 1650, raja Sumbawa, Mas Dini, menikah dengan puteri raja Tallo. Pada 29 Juni 1684, Mas Bantam, pendiri kerajaan Sumbawa dinasti Dewa Dalam Bawa bergelar Sultan Harunnurasyid I (1674-1702) menikah dengan putri raja Goa. Selanjutnya, putera kedua Sultan Harunnurasyid I, Mas Madina, yang kemudian menjadi raja dengan gelar Sultan Jalaluddin Muhammad Syah I (1702-1723), menikahi puteri raja Goa lainnya.

Pernikahan silang antar kerajaan ini dapat dikatakan sebagai perkawinan politik antara kerajaan Goa dengan kerajaan Sumbawa. Adapun Raja Sumbawa yang berkaitan langsung dengan pembangunan Istana Dalam Loka adalah Sultan Muhammad Jalaluddin Syah III (18831931), yang merupakan Sultan ke-16 dari dinasti Dewa Dalam Bawa. Sultan Muhammad Jalaluddin Syah III ini mendapat peneguhan sebagai penguasa Sumbawa berdasarkan akte Pemerintah Kolonial Hindia Belanda tanggal 18 Oktober 1885 dan mulai saat itulah penjajahan kerajaan Belanda berlangsung secara efektif di wilayah kerajaan Sumbawa. Luas wilayah kerajaan Sumbawa berdasarkan Lange Politick Contract 1938 adalah 844 km2, yang secara geografis merupakan sebagian dari Pulau Sumbawa yang terletak pada posisi $116035^{\prime} \mathrm{BB}-118015^{\prime}$ BT dan 80 5' BU-90 5'-LS.

Lokasi Istana Tua (Dalam Loka) pada saat ini terletak di dalam Kota Sumbawa Besar, menunjukkan bahwa kota ini memang sejak dahulu kala merupakan pusat pemerintahan dan pusat kegiatan perekonomian di wilayah Sumbawa. Istana 
Tua Dalam Loka dibangun pada zaman pemerintahan Sultan Muhammad Jalaluddin Syah III, tepatnya pada tahun 1885 . Sebelum istana ini dibangun, kerajaan Sumbawa telah beberapa kali berganti istana, antara lain pernah dikenal Istana Gunung Setia, Istana Bala Balong dan Istana Bala Sawo. Bala Rea (Graha Besar) yang terletak di dalam komplek istana Dalam loka berbentuk rumah panggung kembar, disangga 99 tiang jati yang melambangkan 99 sifat Allah (Asma'ul Husna). Istana ini selain untuk menempatkan raja pada posisi yang agung, juga sebagai pengganti Istana Bala Sawo yang hangus terbakar letusan bubuk mesiu logistik kerajaan. Bangunan Bala Rea ini menghadap ke selatan lurus ke depan alunalun, ke arah bukit Sampar yang merupakan situs makam para leluhur. Di sebelah barat alun-alun terdapat Masjid kerajaan, Masjid Nurul Huda yang masih berdiri hingga sekarang, dan di sebelah timur komplek istana mengalir sungai Brang Bara (sungai di sekitar kandang kuda istana). Bahan baku pembangunan istana Dalam Loka ini sebagian besar didatangkan dari pelosokpelosok desa di sekitar istana. Khusus untuk kayu jati ukuran besar didatangkan dari hutan Jati Timung, sedangkan atapnya yang terbuat dari seng didatangkan dari Singapura. Pekerjaan pembangunan istana ini dipimpin oleh Imam Haji Hasyim.

Bala Rea ini memiliki banyak ruangan dengan fungsinya masing-masing. Antara lain sebagai berikut:

1. Lunyuk Agung, terletak di bagian depan. Merupakan ruangan tempat dilangsungkannya musyawarah, resepsi, dan serangkaian kegiatan penting lainnya.

2. Lunyuk Mas, adalah ruangan khusus bagi permaisuri, para isteri menteri dan staf penting kerajaan ketika dilangsungkan upacara adat. Letaknya bersebelahan dengan Lunyuk Agung.

3. Ruang Dalam sebelah barat, terdiri dari kamar-kamar yang memanjang dari arah selatan ke utara sebagai kamar peraduan raja (Repan) yang hanya disekat kelambu dengan ruangan sholat. Di sebelah utara Ruang Dalam merupakan kamar tidur Permaisuri bersama dayangdayang.

4. Ruang Dalam sebelah timur, terdiri atas empat kamar, diperuntukkan bagi putra putri Raja yang telah berumah tangga. Di ujung utara terletak kamar pengasuh rumah tangga.

5. Ruang Sidang, terletak pada bagian utara (belakang) Bala Rea. Pada malam hari ruangan ini digunakan sebagai tempat tidur para dayang.

6. Dapur terletak berdampingan dengan ruang perhidangan.

7. Kamar mandi, terletak di luar ruang induk, yang memanjang dari kamar peraduan raja hingga kamar permaisuri.

8. Bala Bule, terletak persis di depan ruang tamu permaisuri (Lunyuk Mas), berbentuk rumah dua susun.

9. Lantai pertama yang sejajar dengan Bala Rea berfungsi sebagai tempat putra-putri raja bermain, sedangkan lantai dua menjadi tempat Permaisuri beserta istri para bangsawan menyaksikan pertunjukkan yang dilangsungkan di lapangan istana.

10. Diluar bangunan Bala Rea yang kini dikenal sebagai Dalam Loka, yang merupakan kesatuan dari keseluruhan komplek Istana (Dalam), pada zaman dahulu masih terdapat beberapa bagian penting istana, yakni Keban Alas (kebun istana), Bala Buko (gapura) tembok istana, Bale Jam (rumah jam), tempat khusus diletakannya lonceng kerajaan.

11. Sejak dibangun kembali istana baru, pada tahun 1932 (istana kerajaan yang sejak tahun 1954 difungsikan sebagai rumah dinas "Wisma Praja" Bupati Sumbawa), keadaan Bala Rea sebagai bangunan utama dari komplek istana dalam loka sudah tidak layak ditempati dan mulai ditinggalkan penghuni keturunan kerajaan, sehingga terlantar. Maka tak heran bila ketika mulai dipugar kembali oleh Direktorat Jenderal Kebudayaan pada tahun 1979, melalui Proyek Sasana Budaya-Budaya sejak tahun anggaran 1979/1980 sampai dengan tahun anggaran 1984/1985.

Arsitektur Istana Tua (Dalam Loka) 
Arsitektur Dalam Loka sebagai istana memiliki bentuk yang istimewa, tidak sama seperti bangunan-bangunan umum yang berdiri disekitarnya. Bangunan Dalam Loka berukuran luas 696,98 m2 ditopang oleh tiang sebanyak 99 buah, namun sekarang berjumlah 96 buah. Bilangan tiang sebanyak 99 tersebut untuk mengingatkan agar Raja dalam menjalankan pemerintahan hendaknya mengadaptasi 99 sifat Tuhan, yaitu, rahman/pengasih, rahim/penyayang dan seterusnya. Sedangkan tangga yang menjadi pintu masuk ke istana, mengambil bentuk sebuah pendakian yang mengadung konsep nilai bahwa siapapun seyogyanya menaruh hormat kepada Raja. Hal ini dinyatakan, melalui sikap tubuh yang membungkuk manakala memanjat tangga istana. Susunan ruangan dalam istana yang asli terdiri dari beberapa bagian antara lain: Lunyuk Agung yakni ruangan depan atau balairung, tempat untuk musyawarah, penerima tamu-tamu agung, resepsi kerajaan, upacara-upacara adat dan sebagainya. Bagian barat terdapat beberapa kamar yaitu kamar sholat atau sembahyang, kamar peraduan Sri Sultan serta kamar untuk tuan putri beserta dayangdayangnya. Bagian timur terdapat empat buah kamar dipergunakan bagi putra dan putri Sultan yang sudah berumah tangga serta pejabat istana yang berstatus kepala rumah tangga kerajaan. Bagian tengah antara kamar-kamar sebelah timur dan barat merupakan ruangan besar memanjang, berfungsi sebagai tempat untuk mengatur hidangan untuk segala macam upacara adat dan selamatan, sedangkan pada hari-hari biasa merupakan ruangan untuk berkumpul, berinteraksi para anggota keluarga istana. Selain itu pada malam hari ruangan tersebut dimanfaatkan untuk ruang tidur. Aslinya, di luar bangunan induk sebelah barat arah memanjang terdapat jamban Sri Sultan dan permaisuri serta para tuan putri. Di samping itu juga terdapat sebuah Bala Bulo atau anjunganjung berbentuk rumah susun berlantai tiga. Bagian bawah untuk tempat tidur para putri yang belum berumah tangga, bagian atasnya khusus untuk para putri raja berikut keluarga istana yang wanita dan para dayang-dayangnya. Dikala ada keramaian pada upacara-upacara adat, maka bagian atas ini berfungsi pula sebagai tribune untuk menonton. Bekas istana Sultan Sumbawa yang lebih dikenal dengan Dalam Loka, kini tidak lagi berdiri kokoh seperti sebelumnnya. Beberapa tahun terakhir, Istana Tua yang menjadi icon sejarah ini mengalami renovasi total. Sejak 1994 bangunan Istana Tua berubah fungsi menjadi museum daerah. Hal ini dimaksudkan selain untuk melestarikan bangunan Dalam Loka, juga dihajatkan sebagai tempat menyimpan benda purbakala yang ada di daerah ini. Tanggal 1 Maret 1994 Dalam Loka resmi menjadi Museum sesuai Keputusan Bupati Sumbawa bernomor 118/1994. Sejak saat itulah semua benda purbakala yang masih bisa diselamatkan disimpan di Dalam Loka, seperti geologika, etnografika, arkeologika, historika dan yang sejenisnya.

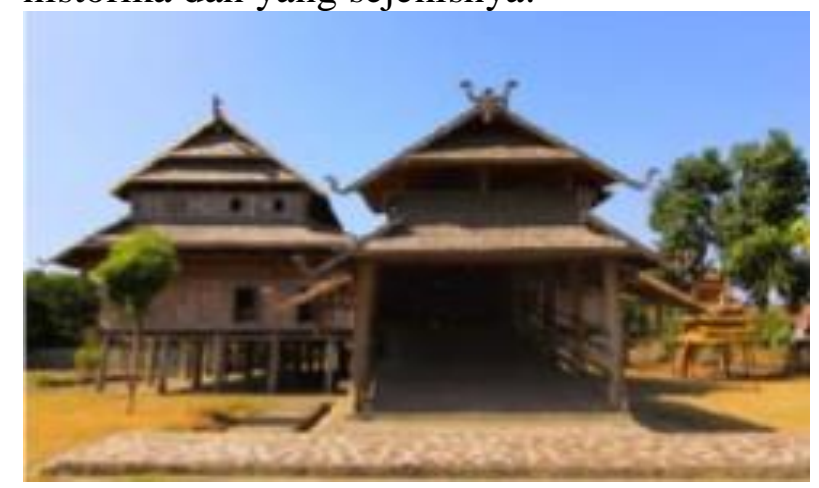

Gambar 2. Arsitektur Istana Tua (Chairil, 2017)

Ada beberapa hal yang menjadi catatan yang berhubungan dengan Istana Tua dari hasil observasi pada saat berkunjung ke Sumbawa, antara lain: Orientasi Bangunan Bangunan Istana Dalam Loka menghadap ke arah selatan. Dari beberapa sumber dijelaskan bahwa arah hadap ke selatan memiliki makna "berpijak pada masa lalu", artinya Sultan sebagai pemimpin harus bijaksana mengambil hikmah dari kejadian masa lalu untuk kebaikan masa kini. Arah hadap ke selatan ini juga diyakini dapat memberikan suasana sejuk, nyaman dan tentram bagi segenap penghuninya. Bangunan Istana Dalam Loka menghadap lurus ke depan alun-alun kearah bukit Sampar yang merupakan situs makam para leluhur. Posisi Istana Dalam Loka tidak 
berhadapan dengan Masjid Kesultanan yang berdekatan di lingkungannya. Hal ini memberikan nilai toleransi bagi penghuni istana yang tidak sempat sholat berjamaah di masjid. Oleh sebab itu di dalam Istana Dalam Loka disediakan musholla.

Sistem Sirkulasi dan Hirarki Bangunan Istana Dalam Loka dapat dicapai dari arah selatan dan dari arah utara. Pada kedua arah tersebut terdapat pintu gerbang, yang mana gerbang utama dari arah selatan sifatnya lebih formal, sehingga dapat berfungsi sebagai pintu utama langsung menuju tangga masuk utama Istana Dalam Loka. Jalan masuk utama menuju bangunan ini tidak dilengkapi dengan anak tangga, melainkan berupa papan yang disusun sedemikian rupa menanjak kearah lantai ruang tamu Istana Dalam Loka. Susunan papan disengaja dibuat sedemikian rupa agar setiap orang yang hendak masuk ke dalam istana posisi tubuhnya merunduk, yang melambangkan penghormatan bagi raja. Kesan ruang mulai dari pintu masuk utama di bagian selatan menuju Istana melalui tangga beratap yang memiliki langitlangit tinggi terasa adanya hirarki berjenjang secara horizontal dan vertikal dengan fungsi yang jelas menuju ruang utama, Lunyuk Agung.

\section{KESIMPULAN}

Adapun Kesimpulan yang dapat diambil dalam penelitian ini adalah bahwa Berdasarkan pengamatan tanda visual Rumah Tinggal Tradisional Sumbawa, ketiga strata memiliki ciri-ciri yang dapat dihubungkan dengan kode, hirarki, fungsi dan nilai yang berbeda sesuai wujud tanda visual arsitekturalnya. Dalam Loka, dengan kode bentuk bersusun secara simetri, tangga beratap ditengah sebagai tempat yang formal dan agung, hiraki berjenjang secara horisontal dan vertical berfungsi sebagai Lokasi Istana Dalam Loka pada saat ini terletak di Kota Sumbawa Besar, Kabupaten Sumbawa Provinsi Nusa Tenggara Barat. Rumah Tradisional Dalam Loka yang ada di Sumbawa Besar dahulu kala merupakan pusat pemerintahan dan pusat kegiatan perekonomian. Istana Tua "Dalam Loka" dibangun pada zaman pemerintahan Sultan Muhammad Jalaluddin Syah III, tepatnya pada tahun 1885. Sebelum istana ini dibangun, kerajaan Sumbawa telah beberapa kali berganti istana, antara lain pernah dikenal Istana Gunung Setia, Istana Bala Balong dan Istana Bala Sawo. Beberapa bentuk rumah adat dalam loka seperti repan shalat, lawang rare, lunyuk agung, lunyuk emas, alang aji, alang kamutar, paladang, tete gasa, tete sawai dan tiang kuntung adalah cerminan dari sistem nilai budaya yang melahirkan perilaku komunal dalam tatanan kehidupan masyarakat Samawa, seperti budaya gotong royong, musyawarah, toleransi, budaya menghormati tamu, budaya bersih dan cinta lingkungan, sikap religi, serta budaya menghormati pemimpin.

\section{DAFTAR PUSTAKA}

Chairil Budiarto, 2017. Semiotika Arsitektur Tradisional Sumbawa.Jurnal RUAS, Volume 15 No 2, Desember 2017, ISSN 1693-3702

Hamid, Abu. 1978. "Catatan tentang Beberapa aspek Kebudayaan Sulawesi Selatan: Bingkisan Kebudayaan. No. 4.

Henny Gambiro, Ahmad Yamin, 2018. Meneropong Istana Tua (Dalam Loka) Warisan Arsitektur Tradisional Sumbawa (Inheritance On Traditional Architecture Of Sumbawa Jurnal Arsitektur, Bangunan, \& Lingkungan | Vol.8 No.1 Oktober $2018: 1-1$

Limpo, Syahrul Yasin. 1995. Profil Sejarah Budaya dan Pariwisata Gowa. Gowa: Pemda Tk.II Gowa kerja sama Yayasan Eksponen 1966.

Mardanas, Izarwisma et.al. 1985. Arsitektur Tradisional Daerah Sulawesi Selatan. Direktorat Jenderal Kebudayaan, Publikasi dan Dokumentasi Kebudayaan Daerah Sulawesi Selatan: Departemen Pendidikan dan Kebudayaan.

Pangerang, Rimba Alam A.et al. 2004. Rapoport, A. (1969). House Formand Culture. London: Prentice Hall, inc. 
Ronald, Arya. (2008). Kekayaan dan Kelenturan Arsotektur. Surakarta : Muhammadiyah University Press. 